\title{
METABOLISM ANALYSIS IN MICE WITH REDUCED CITRATE SYNTHASE ACTIVITY
}

\author{
Andrej Fokin ${ }^{1}$, Petras Minderis' ${ }^{1}$, Rasa Žūkienè2, Aivaras Ratkevičius ${ }^{1}$ \\ Lithuanian Sports University', Kaunas, Lithuania \\ Vytautas Magnus University², Kaunas, Lithuania
}

\begin{abstract}
Background. Citrate synthase (CS) plays an important role in the regulation of carbohydrate oxidation. Variation in citrate synthase activity has an influence on metabolic changes. We tested the hypothesis that reduced mitochondrial CS activity could affect energy expenditure (EE) and respiratory quotient (RQ) in mouse model with an emphasizing on gender differences between tested strains.

Methods. 16-week of age wild-type C57B1/6J (B6) mouse strain, B6.A-(rs3676616-D10Utsw1)/Kjn (B6.A) and $\mathrm{C} 57 \mathrm{BL} / 6 \mathrm{~J}-\mathrm{Chr} 10 \mathrm{~A} / \mathrm{J} / \mathrm{NaJ}$ (B6.A10) strains with reduced CS activity were studied in physiocage by the "Panlab" metabolism analysing equipment. The following parameters were calculated: $\mathrm{EE}\left(\mathrm{ml} / \mathrm{min} / \mathrm{kg}^{\wedge} 0.75\right), \mathrm{RQ}$, physical activity and rearing.

Results. In female mice EE values were lower in B6.A10 strain compared to wild-type B6 strain. RQ values were similar in all tested mouse strains. In B6 mice EE was higher in females compared to males. Rearing was elevated in females of B6 mice compared to males.

Conclusions. EE was lower in B6.A10 compared to B6 mice. Gender differences were noticed only in B6 mice: $\mathrm{EE}$ and rearing were significantly higher in female compared to male mice. Current study did not reveal any other association between reduced CS activity and EE or RQ variation in male and female mice.
\end{abstract}

Keywords: energy expenditure, respiratory quotient, physical activity, gender effect.

\section{INTRODUCTION}

$\gamma^{i}$

itrate synthase (CS) is a key enzyme in Krebs cycle and a marker of mitochondrial content and function (Boushel et al., 2007; Larsen et al., 2012; Ruderman, Saha, Vavvas, \& Witters, 1999). CS plays a central role in the regulation of substrate oxidation by mitochondria (Ruderman et al., 1999) and in carbohydrate metabolism. CS activity depends on many metabolism processes and can be increased, for instance, by respiratory muscle training or during endurance exercise training (Holloszy \& Booth, 1976; Jaenisch, Bertagnolli, Borghi-Silva, Arena, \& Lago, 2017). Our recent studies showed similar results: mice with reduced CS activity had substantially lower endurance capacity compared to control mice with no sex effect on endurance performance (Kvedaras et al., 2017). These facts suggest that variation in CS activity may influence metabolic changes. There is evidence that increased CS activity could have a negative effect on the metabolism. For example, after a meal, carbohydrate oxidation may inhibit fatty acid oxidation in mitochondria (Ranneries et al., 1998). Because of high CS activity the elevated concentration of citrate (one of the carbohydrate substrates in Krebs cycle synthesized by the influence of CS enzyme) in cytosol may indirectly inhibit the metabolism of fats, which leads to obesity and insulin resistance (Bays, Mandarino, \& DeFronzo, 2004; Rogge, 2009). Therefore, Cs gene may be a pharmacological target to treat obesity. There is still lack of data, how reduced CS activity affects energy expenditure and respiratory quotient in mice. 
Also, limited number of studies addresses gender effect on metabolism despite the fact that this effect exists, especially in mitochondrial metabolism features (Thompson et al., 2013). The differences between male and female mice may be a crucial factor in analysing point mutation, such as $\mathrm{H} 55 \mathrm{~N}$ polymorphism studied in the current experiment and its consequence - reduced CS activity (Ratkevicius et al., 2010). Higher estrogen levels in females could be a possible explanation of variation between males and females. Hence, controversial results are presented where no differences in heart, skeletal muscle and liver mitochondrial oxygen consumption were observed between male and female C57BL/6J mice (Sanz et al., 2007). It is known that respiration mechanics in lungs differs between male and female mice. A possible explanation for this finding is that the larger lung volume of female mice is adapted to higher metabolic and oxygen demands during pregnancies and lactation (Schulz et al., 2002).

Energy balance depends on the mechanisms that regulate basal metabolism, energy expenditure, respiratory quotient and physical activity. Respiratory quotient is an indirect mark to estimate energy imbalance in metabolism process (Longo et al., 2010). These metabolism parameters may be strain and gender dependent. For example, females have greater global $\mathrm{O}_{2}$ consumption, which is indicative of higher energy expenditure than that of males in rat model (Rodriguez-Cuenca et al., 2002).

The aim of the study was to test the hypothesis if reduced CS activity could affect energy expenditure and respiratory quotient in male and female mice. Thus we investigated three strains: control C57BL/6J (B6) strain with normal CS activity, congenic B6.A-(rs3676616-D10Utsw1)/ KjnB6 (B6.A) and consomic C57BL/6J-Chr 10A/J/ $\mathrm{NaJ}$ (B6.A10) strains with reduced CS activity.

\section{METHODS}

Animals. All the procedures were approved by the Lithuanian State Food and Veterinary Service (No. 0223). Mice were kept in standard cages (cage dimensions: $267 \times 207 \times 140 \mathrm{~mm})$ at $20-22^{\circ} \mathrm{C}$ temperature and $55 \pm 10 \%$ humidity with $12 / 12 \mathrm{~h}$ light/dark cycle. Mice fed for standard rodent diet $(58.0 \% \mathrm{kcal}$ from carbohydrate, $28.5 \% \mathrm{kcal}$ from protein, $13.5 \% \mathrm{kcal}$ from fat; LabDiet 5001, LabDiet, St. Louis, USA) and received tap water ad libitum.
For metabolism experiment 16 week-old mice were chosen: control C57BL/6J (B6) mice with normal CS activity, B6.A-(rs3676616-D10Utsw1)/Kjn (B6.A) mice, carrying H55N polymorphism which is associated with reduced CS activity (Ratkevicius et al., 2010) and C57BL/6J-Chr 10A/J/NaJ (B6.A10) mice, carrying $\mathrm{A} / \mathrm{J}$ chromosome 10 of $\mathrm{B} 6$ mice, this substitution is also associated with reduced citrate synthase activity (Kvedaras et al., 2017). Both male $(n=9$ for each strain) and female $(n=9$ for each strain) mice were studied. Mice were purchased from Jackson laboratory (Bar Harbor, USA).

Metabolism measurements. B6, B6.A and B6.A10 strains were studied by Panlab metabolism system (Panlab Harvard Apparatus, Barcelona, Spain). The following metabolic parameters were assessed by a gas analyser (LE405, Panlab Harvard Apparatus, Barcelona, Spain): daily energy expenditure (EE, $\mathrm{ml} / \mathrm{min} / \mathrm{kg}^{\wedge} 0.75$ ) and respiratory quotient (RQ). LE405 was connected to the switching device (LE400, Panlab Harvard Apparatus, Barcelona, Spain). Air flow rate of LE400 was set to $250 \mathrm{ml} / \mathrm{min}$ (optimal for mice metabolism measurements) and the switching time of $3 \mathrm{~min}$, which refers to a transition time between gas concentration measurements in physiocage and the external environment. LE405 had measured $\mathrm{O}_{2}$ and $\mathrm{CO}_{2}$ concentrations in physiocage (Physiocage 00, Panlab Harvard Apparatus, Barcelona, Spain). With Physiocage, mice activity parameters were calculated. The Physiocage system detects changes of kinetic and potential energy produced by animal movement inside the cage. A transducer placed under the cage measured changes of mice activity. LE405 has been calibrated at the high point $(50 \%$ $\left.\mathrm{O}_{2}, 1.5 \% \mathrm{CO}_{2}\right)$ and at the low point $\left(20 \% \mathrm{O}_{2}, 0 \%\right.$ $\mathrm{CO}_{2}$ ) by calibration gas tanks and the calibration protocol provided by LE405 manual prior to the experiment. Final results were calculated by the Metabolism software v1.5.

All the metabolism measurements were performed at light cycle (from 9:00 to 18:00). Each mouse was weighed (Kern, ABS 80-4, Germany) and tested in physiocage for $3 \mathrm{~h}$ ( $1 \mathrm{~h}$ of acclimation and $2 \mathrm{~h}$ of measurements) as a control.

Statistical analysis. Unpaired $t$-test was performed to evaluate differences between the strains and between male and female mice. "Graphpad Prism" and "Microsoft excel" programs were used for statistical analysis. Values of $p<.05$ were considered as statistically significant. Results are presented as mean $\pm S D$. 


\section{RESULTS}

No strain effect on mice body weight was identified with one exception in B6.A males (29.2 \pm $1.2 \mathrm{~g})$, which were lighter than B6 mice $(32.2 \pm$ $1.1 \mathrm{~g})$.

Two main metabolic parameters were measured in physiocage to observe differences between B6, B6.A and B6.A10 mice strains: EE (kcal/day/ $\left.\mathrm{kg}^{\wedge} 0.75\right)$ and RQ.

EE was stable in male mice of all (B6, B6.A and B6.A10) strains (Figure 1A) with no statistical difference $(p>.05)$. In female mice EE values were lower in B6.A and B6.A10 strain with a statistical significance in B6.A10 (191.8 $\pm 13.7 \mathrm{kcal} /$ day/ $\left.\mathrm{kg}^{\wedge} 0.75\right)(\mathrm{p}<.01)$ compared to wild-type B6 strain $\left(169.5 \pm 17 \mathrm{ml} / \mathrm{min} / \mathrm{kg}^{\wedge} 0.75\right)$ (Figure 1B).

RQ values were similar in all (B6, B6.A and B6.A10) strains of male (Figure 1C) and female (Figure 1D) mice with no statistical difference $(p>.05)$. RQ have not exceeded the value of 0.8 .
Metabolism analysis of gender differences in B6, B6.A and B6.A10 strains was performed. In B6 mice EE was significantly higher in females compared to males $(191.8 \pm 13.7$ and $168.2 \pm$ $15.4 \mathrm{kcal} /$ day $/ \mathrm{kg}^{\wedge} 0.75$, respectively) ( $\mathrm{p}<.01$ ), no gender differences were observed in B6.A and B6.A10 strain (Figure 2A). RQ did not differ between male and female mice in all tested strains (Figure 2B).

Additionally, overall physical activity (Figure 2C) and rearing (Figure 2D) parameters were measured in both male and female mice of B6, B6.A and B6.A10 strains. Because of high SD physical activity values calculated in all tested groups, no physical activity differences were identified between male and female mice $(p>.05)$ (Figure 2C). Nevertheless, there was a tendency of higher physical activity in males compared to females. Interestingly, the number of rearing was significantly elevated in females $(p<.05)$ of B6 mice compared to males (Figure 2D).

Figure 1. Strain effect on energy expenditure $(A, B)$ and respiratory quotient $(C, D)$ in B6, B6.A and B6.A10 male and female mice
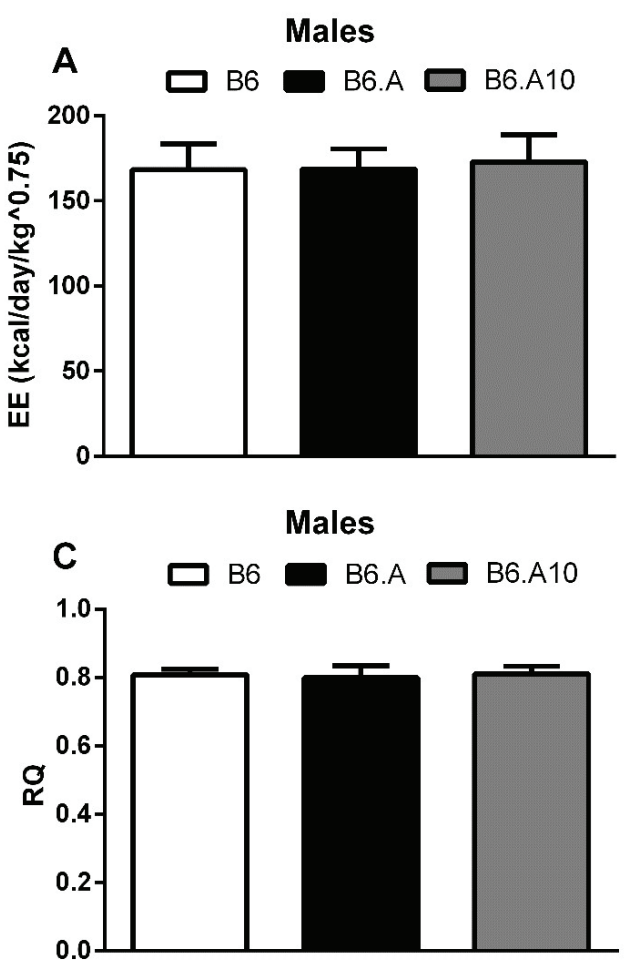
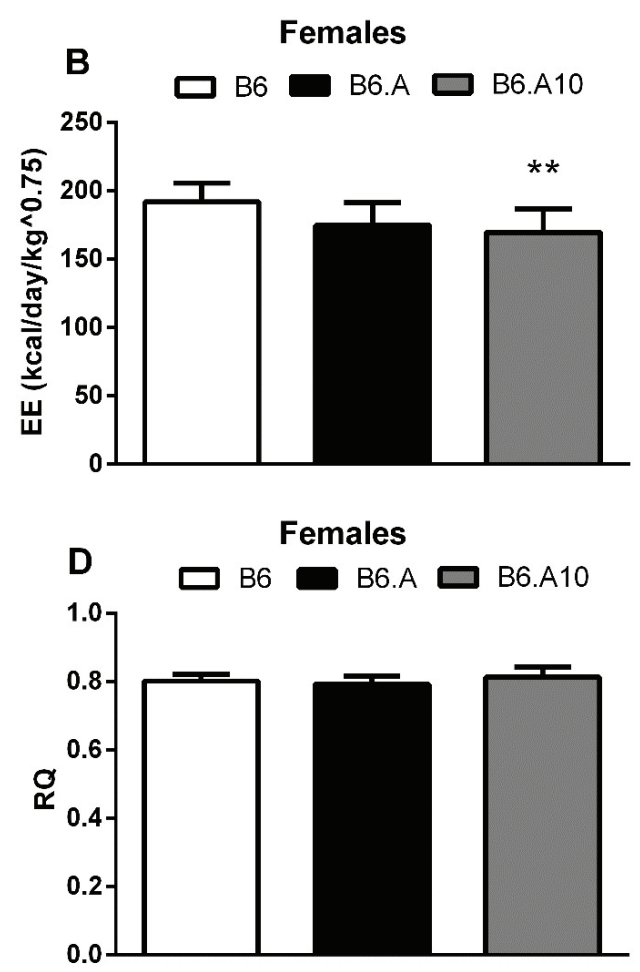

Note. $* * \mathbf{p}<.01$ vs. B6 strain. 
Figure 2. Energy expenditure (A), respiratory quotient (B), physical activity (C) and rearing (D) gender differences in B6, B6.A and B6.A10 mice
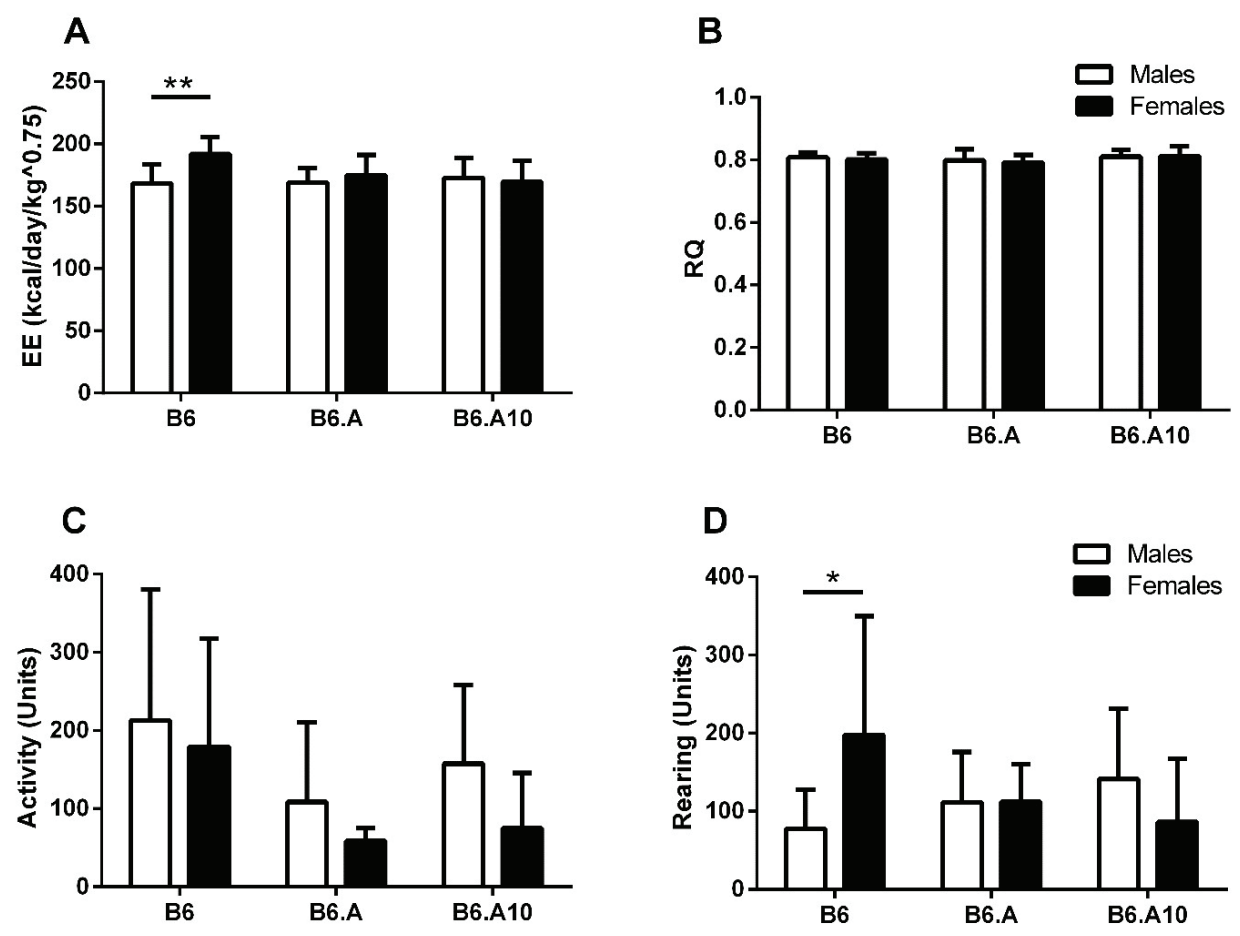

Notes. $* p<.05, * * p<.01$ vs. females.

\section{DISCUSSION}

The main aim of the study was to investigate if reduced citrate synthase (CS) activity could affect metabolism in $\mathrm{C} 57$ mice. We studied three strains of C57: control B6 with normal CS activity, B6.A and B6.A10 with reduced CS activity. However, we did not observe any significant differences in energy expenditure (EE) and respiratory quotient (RQ) between these strains. One exception was noticed in female mice with significantly lower EE in consomic B6.A10 mice with reduced CS activity compared to control B6 strain. The most interesting part was that $\mathrm{EE}$ did not differ between B6.A and B6.A10 female mice despite the fact that both strains have reduced CS activity. One possible explanation could be different type of mutation in chromosome 10, where Cs gene is localized in mouse model (Johnson, Gagnon, Longo-Guess, \& Kane, 2012). In B6.A strain there is a missense mutation in $C s$ gene, while in B6.A10 whole chromosome 10 is substituted by homologous chromosome (Kvedaras et al., 2017). Therefore we could speculate that other genes in chromosome 10 could affect EE in B6.A10 mice with no association with reduced CS enzyme activity. Also, in the current study no high fat diet intervention was performed to evaluate reduced CS performance and effect on oxidation of free fatty acids. For example, high fat diet significantly affected EE (which was tested by the same Panlab metabolism system as in current study) of C57BL/6 mice in comparison to mice with high fat diet intervention (Cappelli et al., 2014). Further analysis of consomic B6.A10 strain is needed for a more accurate explanation. Stable RQ values estimated in all three tested mouse strains showed that reduced citrate synthase activity under normal conditions (standard rodent diet, no interventions) did not induce energy imbalance in mice metabolism.

We also observed higher energy expenditure values in $\mathrm{B} 6$ female mice $(p<.01)$, suggesting that females exhibited more energy in comparison to males. One study showed high energy uptake 
efficiency in males (Catala-Niell, Estrany, Proenza, Gianotti, \& Llado, 2008). However, more studies with mice models are necessary before reaching final conclusions with the gender effect on mice respiration properties. It is known that females have greater tissue recruitment, which is reflected mainly in their mitochondrial features. These could be responsible, at least in part, for the differences in energy expenditure found between genders (Quevedo, Roca, Pico, \& Palou, 1998; Rodriguez-Cuenca et al., 2002). The interesting part is that rearing was also significantly higher in $\mathrm{B} 6$ female mice $(p<.05)$. Therefore another possible mechanism of higher EE in B6 female mice compared to males may be higher energy demands because of increased number of rearing during the metabolism experiment.

In summary, our study has revealed one association between reduced CS activity and EE variation in female mice only with no association of RQ with missense mutation in $C S$ gene.

\section{CONCLUSIONS}

1. Energy expenditure in B6.A10 female mice with reduced citrate synthase activity was statistically significantly lower in comparison to wild-type B6 mice.

2. Energy expenditure and rearing were significantly higher in $\mathrm{B} 6$ female mice compared to B6 male mice.

\section{REFERENCES}

Bays, H., Mandarino, L., \& DeFronzo, R. A. (2004). Role of the adipocyte, free fatty acids, and ectopic fat in pathogenesis of type 2 diabetes mellitus: Peroxisomal proliferator-activated receptor agonists provide a rational therapeutic approach. Journal of Clinical Endocrinology \& Metabolism, 89(2), 463-478. doi: 10.1210/jc.2003030723

Boushel, R., Gnaiger, E., Schjerling, P., Skovbro, M., Kraunsoe, R., \& Dela, F. (2007). Patients with type 2 diabetes have normal mitochondrial function in skeletal muscle. Diabetologia, 50(4), 790-796. doi: 10.1007/ s00125-007-0594-3

Cappelli, A. P., Zoppi, C. C., Barbosa-Sampaio, H. C., Costa, J. M., Jr., Protzek, A. O., Morato, P. N., . . Carneiro, E. M. (2014). Taurine-induced insulin signalling improvement of obese malnourished mice is associated with redox balance and protein phosphatases activity modulation. Liver International, 34(5), 771-783. doi: 10.1111/liv.12291

Catala-Niell, A., Estrany, M. E., Proenza, A. M., Gianotti, M., \& Llado, I. (2008). Skeletal muscle and liver oxidative metabolism in response to a voluntary isocaloric intake of a high fat diet in male and female rats. Cellular Physiology and Biochemistry, 22(1-4), 327-336. doi: 10.1159/000149811

Holloszy, J. O., \& Booth, F. W. (1976). Biochemical adaptations to endurance exercise in muscle. Annual Review of Physiology, 38, 273-291. doi: 10.1146/ annurev.ph.38.030176.001421

Jaenisch, R. B., Bertagnolli, M., Borghi-Silva, A., Arena, R., \& Lago, P. D. (2017). Respiratory muscle training improves diaphragm citrate synthase activity and hemodynamic function in rats with heart failure. Brazilian Journal of Cardiovascular Surgery, 32(2), 104-110. doi: 10.21470/1678-9741-2017-0002
Johnson, K. R., Gagnon, L. H., Longo-Guess, C., \& Kane, K. L. (2012). Association of a citrate synthase missense mutation with age-related hearing loss in A/J mice. Neurobiology of Aging, 33(8), 1720-1729. doi: 10.1016/j.neurobiolaging.2011.05.009

Kvedaras, M., Minderis, P., Fokin, A., Ratkevicius, A., Venckunas, T., \& Lionikas, A. (2017). Forced running endurance is influenced by gene(s) on mouse chromosome 10. Frontiers in Physiology, 8, 9. doi: 10.3389/fphys.2017.00009

Larsen, S., Nielsen, J., Hansen, C. N., Nielsen, L. B., Wibrand, F., Stride, N., . . Hey-Mogensen, M. (2012). Biomarkers of mitochondrial content in skeletal muscle of healthy young human subjects. Journal of Physiology, 590(14), 3349-3360. doi: 10.1113/jphysiol.2012.230185 Longo, K. A., Charoenthongtrakul, S., Giuliana, D. J., Govek, E. K., McDonagh, T., Distefano, P. S., \& Geddes, B. J. (2010). The 24-hour respiratory quotient predicts energy intake and changes in body mass. American Journal of Physiology-Regulatory, Integrative and Comparative Physiology, 298(3), R747-754. doi: 10.1152/ajpregu.00476.2009

Quevedo, S., Roca, P., Pico, C., \& Palou, A. (1998). Sexassociated differences in cold-induced UCP1 synthesis in rodent brown adipose tissue. Pflügers Archiv European Journal of Physiology, 436(5), 689-695. doi: 10.1007/ s004240050690

Ranneries, C., Bulow, J., Buemann, B., Christensen, N. J., Madsen, J., \& Astrup, A. (1998). Fat metabolism in formerly obese women. American Journal of Physiology, 274(1 Pt 1), E155-161.

Ratkevicius, A., Carroll, A. M., Kilikevicius, A., Venckunas, T., McDermott, K. T., Gray, S. R., ... . Lionikas, A. (2010). H55N polymorphism as a likely cause of variation in citrate synthase activity of mouse 
skeletal muscle. Physiological Genomics, 42a(2), 96102. doi: 10.1152/physiolgenomics.00066.2010

Rodriguez-Cuenca, S., Pujol, E., Justo, R., Frontera, M., Oliver, J., Gianotti, M., \& Roca, P. (2002). Sexdependent thermogenesis, differences in mitochondrial morphology and function, and adrenergic response in brown adipose tissue. Journal of Biological Chemistry, 277(45), 42958-42963. doi: 10.1074/jbc.M207229200

Rogge, M. M. (2009). The role of impaired mitochondrial lipid oxidation in obesity. Biological Research For Nursing, 10(4), 356-373. doi: 10.1177/1099800408329408

Ruderman, N. B., Saha, A. K., Vavvas, D., \& Witters, L. A. (1999). Malonyl-CoA, fuel sensing, and insulin resistance. American Journal of Physiology, 276(1 Pt 1), E1-e18.
Sanz, A., Hiona, A., Kujoth, G. C., Seo, A. Y., Hofer, T., Kouwenhoven, E., ... Leeuwenburgh, C. (2007). Evaluation of sex differences on mitochondrial bioenergetics and apoptosis in mice. Experimental Gerontology, 42(3), 173-182. doi: 10.1016/j.exger.2006.10.003

Schulz, H., Johner, C., Eder, G., Ziesenis, A., Reitmeier, P., Heyder, J., \& Balling, R. (2002). Respiratory mechanics in mice: Strain and sex specific differences. Acta Physiologica Scandinavica, 174(4), 367-375. doi: 10.1046/j.1365-201x.2002.00955.x

Thompson, J. R., Swanson, S. A., Casale, G. P., Johanning, J. M., Papoutsi, E., Koutakis, P., . . Pipinos, II. (2013). Gastrocnemius mitochondrial respiration: Are there any differences between men and women? Journal of Surgical Research, 185(1), 206-211. doi: 10.1016/j. jss.2013.05.054
Corresponding author Andrej Fokin

Institute of Sport Science and Innovations Lithuanian Sports University

Sporto str. 6, Kaunas LT-44221

Lithuania

Tel. +37060914960

Email andrej.fokin@1su.1t 